\title{
Um violino eloquente - gesto e gestus do violino na cena
}

\section{An eloquent violin - gesture and gestus in the scenic performance}

Barbaro Biscaro ${ }^{1}$

Fernando da Costa Bresolin ${ }^{2}$ 


\section{Resumo}

Neste artigo discutem-se as relações entre música e cena a partir das teorias do gesto musical e do gestus brechtiano. A intersecção das linguagens da música e do teatro nessa discussão específica se consolida a partir de um trabalho prático intitulado Récita - tudo aquilo que chama a atenção, atrai e prende o olhar, espetáculo de música-teatro. $O$ foco do texto é o papel do violino tanto musicalmente quanto em cena, suas especificidades técnicas e as linguagens vinculadas ao instrumento, sublinhando seus aspectos estéticos e históricos aliados á consolidação de um repertório de Brecht e Weill dentro dos procedimentos propostos pelo espetáculo.

Palavras-chave: Gesto. Música-teatro. Brecht. Violino. Weill

\section{Abstract}

On this paper the relationship between music and the scene are discussed departing from the theories of the musical gesture and the gestus from B. Brecht. The link between the languages of music and theatre is made in basis of an practical work called Récita - tudo aquilo que chama a atenção, atrai e prende o olhar, an music-theater performance. The focus of the text is the role of the violin, both from the musically and scenic point of views, its technical specificity and the languages tied to the instrument, underlining its aesthetic and historical aspects linked to the setting of such a Brecht and Weill repertoire inside the procedures of the theatrical performance.

Keywords: artist book, book of hours, poetry

ISSN: 1808-3129 
Este artigo tem como objetivo fazer algumas reflexões sobre os aspectos musicais e dramatúrgicos da construção de um espetáculo de música-teatro ${ }^{1}$ intitulado Récita - tudo aquilo que chama a atenção, atrai e prende o olhar². A base dramatúrgica do espetáculo se constitui em dez canções do compositor alemão Kurt Weill e do dramaturgo também alemão Bertolt Brecht, abarcando obras de 1928 a 1956. As canções, originalmente compostas para canto e formações orquestrais mistas (e versão para canto e piano do próprio Kurt Weill), fazem um apanhado significativo da obra para o Musiktheater - gênero desenvolvido por Brecht e Weill na década de 1920, que inaugura novas formas dramatúrgico-musicais para a junção das linguagens da música e do teatro. No caso do Récita, as canções ganharam a formação voz e violino, o que exigiu transposições musicais e de textura, gerando um resultado particular.

O espetáculo não pretende, portanto, expor a dramaturgia cênico-musical de Weill e Brecht de forma a reconstituir o período de um modo linear ou explicativo: através do processo de bricolagem (fazendo uma forte referência - e consequente ironia - às estruturas dos recitais de música de câmara), a dramaturgia do espetáculo visa um mergulho no universo de Brecht e Weill através dos contrastes. A exploração do grotesco e o estudo das teorias de Brecht para o teatro épico geraram um percurso único e particular. O teatro épico visa a quebra da ilusão do público em relação à verossimilhança da cena, aproximando-se do espectador-ouvinte no processo de contar/mostrar as ações dramáticas dos personagens a fim de gerar um processo reflexivo. As figuras em cena não trabalham na forma tradicional da construção de personagens, mas sim no desenvolvimento de figuras grotescas que contém em si uma fusão entre ator-musicista-bufão, criando uma categoria particular de intérprete e criador da cena.

Essa forma de conceber a dramaturgia dialoga claramente com as proposições de Weill e Brecht na construção de um gênero cênico-musical diferenciado das formas tradicionais da ópera de seu tempo, buscando se opor principalmente à herança deixada pelo drama musical Wagneriano. Segundo os pesquisadores Eric Salzman e Thomas Desi:

E num sentido mais amplo, o neoclassicismo e a neo-tonalidade abraçou elementos tradicionais das formas tonais e modais derivados da forma da música popular e folclórica, bem como da canção popular e do jazz.Também houveram estreitas aproximações com a mudança política, porém mais tarde, em parte sob influências ideológicas, afastou-se da experimentação da avant-garde em favor da acessibilidade e uma forma de apresentação de teatro destinadas a instruir ou provocar tanto quanto entreter ${ }^{3}$ (DESI; SALZMAN, 2010, p.48, trad. nossa).

\footnotetext{
${ }_{1}$ Para saber mais sobre o conceito de música-teatro, ver artigo de BISCARO intitulado Música-teatro: transformações e transposições cênicas em http://www.portocenico.com.br/PortoCenico02.pdf

${ }^{2}$ Espetáculo que estreou em janeiro de 2014. Direção de Barbara Biscaro, com performance dela mesma e Fernando da Costa Bresolin. Para maiores informações www.barbarabiscaro.blogspot.com.br.

${ }^{3}$ In a wider sense, neoclassicism and neo-tonality embraced elements from traditional modal and tonal forms derived from popular and folk music, as well as popular song and jazz. There was also close associations with the political change but later, partly under ideological influences, turned away from avant-garde experimentation in favor of accessibility and a presentational form of theater meant to instruct or provoke as much as entertain. (DESI; SALZMAN, 2010, p.48).
} 
São muito presentes nas obras do repertório do Récita elementos da avantgarde da música européia, como o politonalismo, colocados em diálogo constante com a música popular, como o jazz e as canções de cabaré. A mistura entre erudito e popular, lírico e grotesco é base para uma concepção de música/cena que incorpora um ideal político propagado por Brecht através do seu teatro épico: mais do que entretenimento, o teatro é um espaço político que manifesta ideais e ideologias que devem ser dissecadas diante do olhar do espectador - e não vendidas sedutoramente - a fim de se tornar um instrumento de tomada de consciência.

Os artistas [de Brecht] não "se tornavam" os personagens que estavam representando, mas se apresentavam ao público como atores criando papéis e situações dramáticas para o público considerar. Esse conceito de "peça" foi concebido para chamar o público como um parceiro e participante e, como não frequentemente, o público era literalmente convidado a decidir por si mesmo. (DESI; SALZMAN, 2010, p.48, trad. nossa).

Esse aspecto relacional é bastante presente no Récita, tanto por sua constituição espacial (os performers ficam muito próximos do público) quanto através das texturas sonoras criadas pela transformação do repertório a partir da formação voz e violino: as lacunas criadas pela natureza monódicas dos instrumentos devem ser preenchidas pelo espectador, juntamente com a visualidade e a cinestesia da cena.

\section{O corpo-violino - gesto musical, gestus teatral}

Neste texto, gostaríamos de aprofundar questões referentes ao processo de construção dos arranjos para violino do processo de criação do Récita. É importante frisar que o processo de construção cênico-musical do espetáculo esteve baseado nas concepções do intérprete-criador, ou seja, a subjetividade e a experiência do performer em cena são consideradas fatores principais e únicos: as experiências físicas, emocionais e técnicas do performer influenciam diretamente a construção da dramaturgia, na qual cada pessoa envolvida no processo é igualmente criador e intérprete dos próprios materiais. Essa concepção de criação/atuação dialoga diretamente com as proposições do Terceiro Teatro, conceito criado por Eugenio Barba, diretor teatral e pesquisador italiano. $O$ Terceiro Teatro abarcaria as pesquisas cênicas fortemente voltadas para um teatro de pesquisa no qual o ator/atriz é o epicentro da criação. O texto vira um pré-texto para as improvisações e geração de materiais cênicos que vão constituir a dramaturgia cênica, e no caso do Récita, cênico-musical.

Nesse sentido, os arranjos para violino criados no Récita foram criados a partir da subjetividade e da corporalidade, aliadas ao conhecimento técnico de Fernando Bresolin, colocado em cena não apenas como violinista , mas como ator-musicista, ou seja, sem hierarquia de funções. A criação dos arranjos surgiu das propostas de

\footnotetext{
${ }^{4}$ The performers did not 'become' the characters they were playing but presented themselves to the public as actors creating roles and dramatic situations for the public to ponder. This concept of 'play' was intended to draw in the audience as a partner and participant and, often as not, the public was literally invited to make on his own mind (DESI; SALZMAN, 2010, p. 48).
} 
Bresolin, feitas a priori em um momento de ensaios musicais nos quais se pesquisava formas de disposição de texturas entre voz e violino no repertório, e posteriormente nos ensaios cênicos. Nos jogos de preparação da cena, voz e violino entram em relação de forma completamente diferente, e a presença do violino, em sua musicalidade, passa a se aproximar da noção de gesto musical. Ao colocar o músico e a música como parte do processo cênico, um vinculo diferente se estabelece. O papel do músico/ator servirá novamente como um intermediador, desta vez engendrando linguagem musical/sonora, cena e espectador. Quando gesto e sonoridade se tornam indissociáveis, a música e a cena devem aparecer no mesmo patamar; ator e músico são um só e a própria música torna-se dramaturgia. Mário Carvalho, pesquisador na área de musicologia comenta:

Na visão adorniana, a música, como linguagem, é a única de todas as artes que realiza a pura objetivação do impulso mimético, tanto livre da concreção como da significação, assim, ela não seria outra coisa senão o gesto elevado a lei, gesto acima do mundo corporal e, ao mesmo tempo, "gesto sensorial" (CARVALHO, 2005, p.212).

Assis e Amorim (2009) discorrem sobre a redescoberta do gesto musical, ponderando que apesar de seu aspecto intrínseco ligado a linguagem musical (composição, performance e análise), o gesto pode estar ligado as novas exigências da música contemporânea e, nesta categoria, podemos incluir as formas hibridas de performances cênico-musicais - temos em mente aqui, por exemplo, a obra para flauta doce solo Gesti, de Luciano Berio, endereçada para o flautista Frans Brüggen. No entanto, o gesto na música pode ser observado também em formas mais tradicionais, como por exemplo, no repertório musical do período barroco, que se utiliza das figuras retóricas aplicadas à música (ASSUMPÇÃO, 2013).

A retórica como norteadora da linguagem musical dos sécs. XVII e XVIII pode ser tomada como exemplo da oscilação que o papel do intérprete sofreu em face da obra musical escrita. A eloquência esperada do intérprete naquele período, segundo testemunho de vários autores da época (Quantz, Bach, Geminiani, Mattheson, L. Mozart) demonstra que o eixo entre performer-obra-ouvinte pendia fortemente para o primeiro. Essa situação é invertida nos séculos XIX e XX, no qual se espera do intérprete a neutralidade de um transmissor das idéias sonoras do compositor para o ouvinte. Tomamos como exemplo um Adagio da sonata III op. V, de Arcangelo Corelli (1653-1713), para violino e baixo contínuo. A partitura publicada em 1700 contém apenas música em si, a composição, ou seja, a linha não ornamentada de violino e a linha do baixo contínuo (dentre os vários instrumentos que podem compor o baixo contínuo citamos como exemplos alguns deles: cravo/teorba/alaúde e violoncelo/ viola da gamba). Posteriormente um editor (Etienne Roger, Amsterdam) adicionou uma linha de violino ricamente ornamentada, indicando a maneira que supostamente esta música era tocada, evidenciando o sentido eloquente de seus contornos melódicos. A performance pode ser lida como o final do processo, como podemos observar no exemplo a seguir, onde a obra escrita do compositor deixa aberto, pressupondo a habilidade do intérprete de, neste caso, ornamentar dentro do estilo em voga (regrado pela práxis vigente) e pela sua habilidade. 

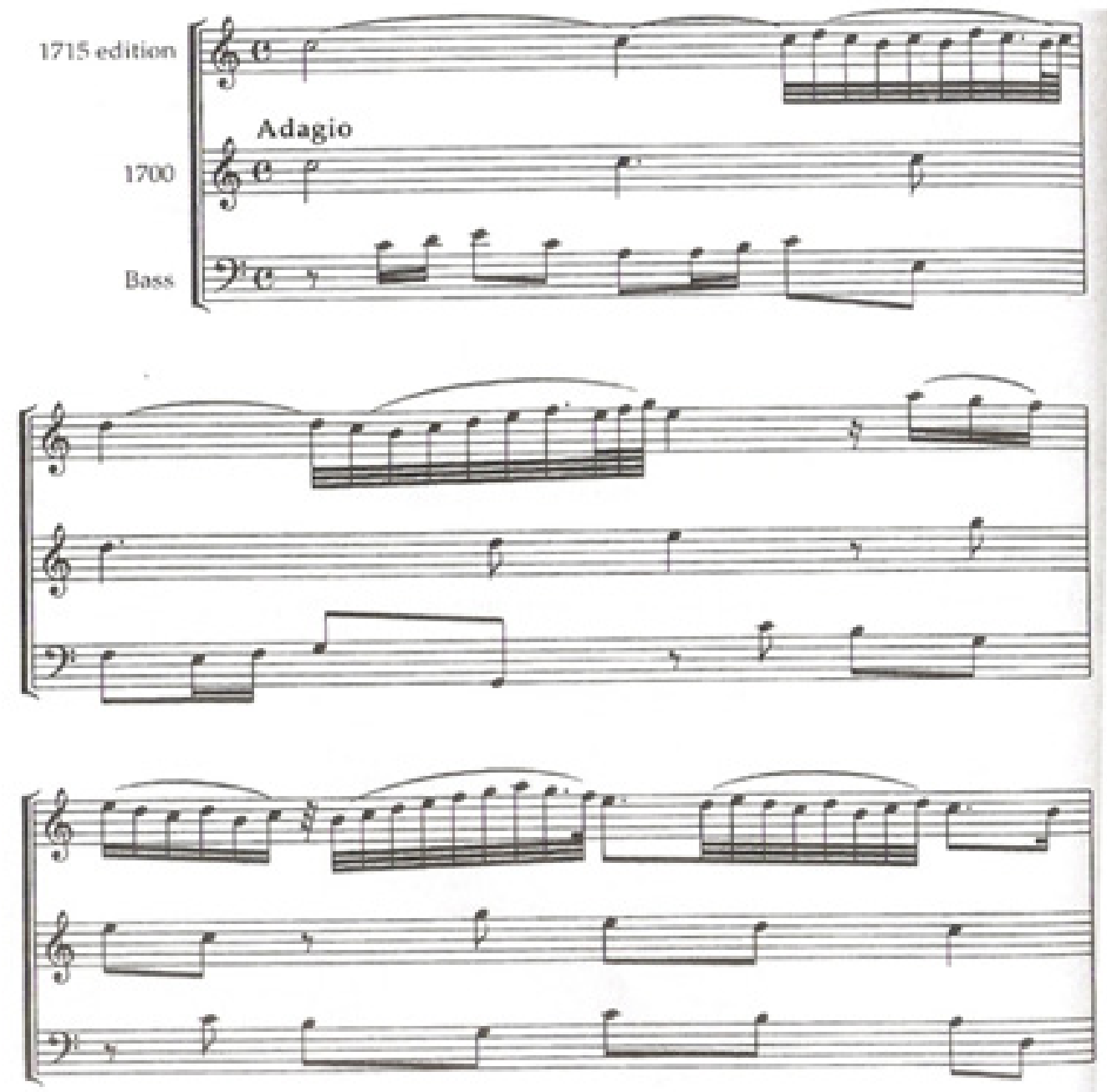

Arcangelo Corelli: Sonata III, Opus V. Edição original de 1700 e edição de Etienne Roger de 1715 "ornamentada" , mostrando uma possibilidade de interpretação da escrita a partir da performance (BOWEN, 1999, p. 426).

A autonomia da música instrumental, em curso de franco desenvolvimento desde o séc. XVII (suítes, sonatas, concertos, música para instrumentos solo diversos) fez surgir a necessidade de novas formas no gênero instrumental para fazer frente aos gêneros vocais já fortemente estabelecidos (ópera, música sacra). Nesse ponto, a ligação entre retórica e música é um importante elo desta transformação:

Ao valorizar as conexões entre elementos a partir de uma idéia final, perseguindo obstinadamente a persuasão do ouvinte, a retórica acaba por determinar a hierarquia das idéias e de seus entrelaçamentos. E, na evolução da linguagem musical, cronologicamente observada, tais pressupostos retóricos precedem o nascimento dos tipos formais, permeando perspicazmente sua gênese. Claro está, portanto, que esta constatação ratifica a ascendência retórica das formas musicais (ASSUMPÇÃO, 2009, p.01).

Diante do repertório para violino deste período, cabia ao intérprete intermediar o texto escrito para o campo sonoro. O gesto musical, então, se transforma em "gesto retórico", e tal efeito é alcançado pelo "instrumento que 'falava' e 'articulava' o texto musical" (FIAMINGHI, 2008, p.37). Nesse caso pode-se concluir que o gesto musical está presente na performance da música instrumental do período barroco, através retórica aplicada as formas musicais. 
A relação corporal que o instrumentista possui com seu instrumento está diretamente ligada à sua produção sonora. Toda a postura do violinista é construída para melhorar sua execução dentro dos padrões técnicos e estéticos vigentes dentro de cada corrente interpretativa e o gesto físico gera a sonoridade. Dessa maneira a partitura (musical) pode ser afetada subjetiva e objetivamente pela outra partitura (a corporal), pois "o movimento corporal desempenha um papel na construção, execução e percepção nas performances musicais [...] todos os músicos usam seus corpos para interagir com seus instrumentos musicais quando executam a música" (DAVIDSON; CORREIA, 2002, p. 237, trad. nossa). Assim, o músico-performer pode se amparar na hermenêutica para compor, não no sentido de reescrever, mas de apropriar-se da obra, e a torna eloquente à exigência da cena, seja ela como um recital de música barroca ou de uma performance contemporânea dependendo do que o gesto exigir.

No tratamento violinístico dos arranjos para o repertório do Récita, o gesto é incorporado na construção do acompanhamento: a linha original da voz é mantida, e, devido a característica monódica do violino, o tratamento predominantemente harmônico das versões para piano é substituído por uma linguagem contrapontística baseada no gesto surgido a partir do jogo de cena. A mimeses sonora dos arranjos não se aproxima, como por exemplo, à mimeses que Antonio Vivaldi apresenta no concerto para violino em Mi Maior intitulado Primavera, no qual a retórica se propõe a imitar o canto dos pássaros em determinado trecho da obra. Neste caso a mimeses surge como um produto do processo gestual físico, resultante da interação entre a cena, o corpo do performer e a música. Os pesquisadores Anthony Gritten e Elaine King escrevem:

Através de diferenças culturais, estéticas e terminológicas, entretanto, a maioria dos estudiosos do gesto musical fundamentam suas suposições amplamente na natureza semiótica: um gesto é um movimento ou mudança de estado que é marcada como um agente significante. Isso para dizer que, para um movimento ou um som se tornarem gesto, devem ser realizados intencionalmente por um intérprete $^{6}[\ldots]$ (GRITTEN; KING, 2006, p. XX, trad. nossa).

A noção tradicional de acompanhamento presente nas versões para piano ou orquestra das canções, sofre com as limitações harmônicas do violino, exigindo assim outros recursos que possam suprir musicalmente as necessidades da obra. É exatamente no intuito de usar essas "limitações" ao nosso favor que se recorreu ao gesto musical, apontando caminhos sonoro/musicais que só poderiam ser propostos e executados por um violino(ista). Para a performance destes arranjos, buscou-se inspiração na técnica da performance da música barroca, em um elemento "antigo" da técnica violinística: o efeito retórico produzido pelo violino(ista) barroco, o "instrumento que falava", abordado por Fiaminghi (2008). Dessa forma a articulação foi utilizada como o sujeito preponderante na performance musical. Ao desobrigar o violino de cumprir um papel essencialmente harmônico e de instrumento acompa-

\footnotetext{
5 "Diz Body movement plays a role in the construction, execution, and perception of musical performances [...] All musicians use their bodies to interact with their musical instruments when performing music. (DAVIDSON; CORREIA, 2002, p. 237)

${ }^{6}$ Across cultural, aesthetic and terminological differences, however, most scholarship on musical gesture makes a grounding assumption, broadly semiotic in nature: a gesture is a movement or change in state that becomes marked as significant by an agent. This is to say that for movement or sound to be (come) gesture it must be taken intentionally by an interpreter [...](GRITTEN; KING, 2006, p. XX).
} 
nhador - deslocando-o para o centro da cena como ator - surgem diferentes possibilidades interpretativas que, derivando da retórica e do gesto musical, colocam o violino como um elemento de diálogo entre a obra originalmente composta e a cena.

Traçando um paralelo entre as teorias do gesto musical e as teorias teatrais, é importante lembrar que Bertolt Brecht é criador da teoria do gestus, que seria o mecanismo concretizador do Verfremdungseffekt - o efeito de distanciamento (ou estranhamento). O efeito de distanciamento/estranhamento, na obra de Brecht, seria o processo através do qual a obra revela ao espectador as contradições inerentes ao que está sendo mostrado em cena: "[...] é preciso que se lide com a realidade na sua complexidade, não amenizando as tensões, mas reconhecendo as suas contradições. [...] O efeito de distanciamento torna-se então o meio através do qual os processos narrativos e a atitude dialética serão traduzidos cenicamente" (BONFITTO, 2002, p. 64). Nesse processo de revelação das contradições, o gestus se concretiza como a articulação das diferentes camadas da construção teatral: não se referindo somente ao corpo do ator, o gestus está em tudo - gestus musical, gestus do figurino, gestus do texto. Vale à pena observar as considerações de Brecht obre o gesto:

Por "gesto" não se deve entender a gesticulação: não se trata de movimento das mãos que têm a finalidade de sublinhar e de esclarecer, mas sim uma atitude de conjunto. "Gestual" é a linguagem que se baseia no gesto assim entendido: uma linguagem que demonstra determinadas atitudes daquele que as assume diante de outras pessoas (BRECHT apud BONFITTO, 2002, p. 65).

O gestus seria, portanto, a construção das contradições constituídas na cena, através das ações de todos os elementos visuais, sonoros e táteis juntos. Um exemplo disso, no caso do Récita, seria o claro contraponto entre a sonoridade lírica associada aos timbres de voz e violino com a constituição grotesca das personagens da cena. No caso do violino, inseparável do corpo e da subjetividade do performer, o seu gestus se concretiza através de diversos mecanismos de ação cênica: comentar, debochar, ameaçar, proteger, dialogar, são algumas ações empreendidas musicalmente e corporalmente em cena, a fim de evidenciar as contradições não só entre voz e violino, mas entre os performers em cena, entre música e espaço, entre ação e texto, e assim por diante. Matteo Bonfitto frisa que "como se pode constatar, a definição de gestus deixa aberto grandes espaços de aplicação" (BONFITTO, 2002, p. 65). Da mesma forma como musicalmente, o espetáculo não se propõe a uma reconstituição da sua época, o uso das teorias de Brecht - que inclui aqui o gestus - foram estopim para a construção da ação da cena e estruturação dramatúrgica, sempre em processo de apropriação e recriação.

As aproximações entre erudito e popular, antigo e avant-garde fazem parte dos processos de construção desse espetáculo. As teorias do gesto musical e o uso dos elementos de retórica inerentes à música barroca para violino desacompanhado - temos em mente aqui a série de Doze Fantasias de G. P. Telemann TWV 40: 14-25, nas quais as oposições entre estilos corelliano e galante constituem a essência de sua força persuasiva - complementam uma discussão importante sobre os modos de criação de música para a cena. Distanciando-se da noção de fundo musical ou da ilustração da cena, violino e violinista, no caso do Récita, se constituem elaboradores 
de dramaturgia cênica, catalisadores de um jogo dialógico. Nesse sentido, a ideia de gestus de Brecht evidencia que a sonoridade do violino nunca é absoluta, mas sempre relacional: seu gestus se compõe em relação com outros elementos da cena, criando camadas de significação. O violino por vezes ironiza, nega, contraria a voz, o texto, a ação da cena, evidenciando contradições construídas dramaturgicamente, alimentando o jogo através dos contrastes de sua sonoridade. As texturas, harmonias e gestos musicais encontrados no processo geraram material para a construção de uma dramaturgia que não constrói hierarquias, posicionando o trabalho final do espetáculo na fronteira entre as linguagens da música e teatro. As pesquisas empreendidas então, apesar de pontuais e particulares, apontam para o amadurecimento de novos procedimentos de junção entre música e cena na contemporaneidade. 


\section{REFERÊNCIAS}

BASSIS, Ana Cláudia. AMORIM, Felipe. O Gesto musical e a expressividade. Aveiro: Performa, 2009.

ASSUMPÇÃO, Sérgio Eduardo Martinelli de. Ascendência Retórica das Formas Musicais. In: Música Hodie, [S.I.], v. 9, n. 3-Esp, jan. 2013. ISSN 2317-6776. Disponível em: <http://www.revistas.ufg.br/index.php/musica/article/view/22003/13091>. Acesso em: 03 Abr. 2014. doi:10.5216/..v9i3-Esp.22003.

BONFITTO, Matteo. O Ator Compositor. São Paulo: Perspectiva, 2002.

BOWEN, José A. Finding Music in Musicology: Performance History and Musical Works. In: COOK, Nicholas; EVERIST, Mark. (Orgs), Rethinking Music. New York: Oxford University Press, 1999, p. 424-451.

CARVALHO, M. V. A Partitura como "Espírito sedimentado": em torno da teoria da interpretação musical de Adorno. In DUARTE, R. (org.). Theoria Aesthetica. Porto Alegre: Escritos Editora, 2005, p. 203-224.

DAVIDSON, Jane; CORREIA, Jorge Salgado. Body Movement. In: PARNCUT, Richard; MCPHERSON, Gary. The Science and Psychology of Music Performance : Creative Strategies for Teaching and Learning. New York: Oxford University Press, 2002, p. 237-255.

DESI, Eric; SALZMAN, Thomas. The new music theater: seeing the voice, hearing the body. New York: Oxford University Press, 2008.

FIAMINGHI, Luiz Henrique. O Violino Violado: rabeca, hibridismo e desvio do método nas práticas interpretativas contemporâneas - Tradição e inovação em José Eduardo Gramani. Doutorado em Música, Campinas: Universidade Estadual de Campinas, 2008.

GRITTEN, Anthony. KING, Elaine. Music and Gesture. England: Ashgate Publishing, 2006. 